\title{
(IL)LOGICAL KNOWLEDGE MANAGEMENT
}


This page intentionally left blank 


\title{
(IL)LOGICAL KNOWLEDGE MANAGEMENT: A GUIDE TO KNOWLEDGE MANAGEMENT IN THE 21 ST CENTURY
}

\author{
BY \\ BEVERLY WEED-SCHERTZER
}

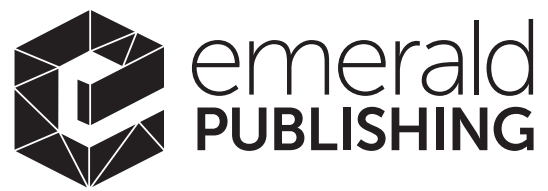

United Kingdom - North America - Japan - India Malaysia - China 
Emerald Publishing Limited

Howard House, Wagon Lane, Bingley BD16 1WA, UK

First edition 2020

Copyright (C) 2020 Emerald Publishing Limited

Reprints and permissions service

Contact: permissions@emeraldinsight.com

No part of this book may be reproduced, stored in a retrieval system, transmitted in any form or by any means electronic, mechanical, photocopying, recording or otherwise without either the prior written permission of the publisher or a licence permitting restricted copying issued in the UK by The Copyright Licensing Agency and in the USA by The Copyright Clearance Center. Any opinions expressed in the chapters are those of the authors. Whilst Emerald makes every effort to ensure the quality and accuracy of its content, Emerald makes no representation implied or otherwise, as to the chapters' suitability and application and disclaims any warranties, express or implied, to their use.

British Library Cataloguing in Publication Data

A catalogue record for this book is available from the British Library

ISBN: 978-1-83867-806-7 (Print)

ISBN: 978-1-83867-803-6 (Online)

ISBN: 978-1-83867-805-0 (Epub)

ISOQAR certified

Management System

awarded to Emerald

for adherence to

Environmental

standard

ISOQAR

ISO 14001:2004.

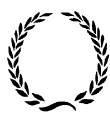

INVESTOR IN PEOPLE 


\section{CONTENTS}

List of Figures vii

List of Tables ix

About the Author $\quad x i$

Preface xiii

Acknowledgments xvii

Introduction xix

1. Sources and Segmentation 1

Knowledge Strategy 5

Data, Information, Knowledge, (II)Logical Knowledge 10 Implementing a Knowledge Plan 19

Case Study - Part $1 \quad 23$

Logical Knowledge as an Asset $\quad 27$

Logical Knowledge 31

Knowledge Trail 36

Knowledge Sources 38

Knowledge Content Segmentation $\quad 45$

Logical Knowledge Environment Benefits $\quad 50$

2. (II)Logical Knowledge Process 53

Context for Content 61

Culture and Collaboration 64

Knowledge Transfer Rules $\quad 71$

Knowledge Distribution Rules $\quad 72$

Logical Knowledge Management Process $\quad 75$

Case Study - Part 1 (Addendum) 80 
3. Tools for Knowledge and Organizational Learning 83 Knowledge Management and Organizational Learning 102 $\begin{array}{ll}\text { Measuring Success } & 107\end{array}$ Case Study - Part $2 \quad 109$ $\begin{array}{ll}\text { Conclusion } & 114\end{array}$

$\begin{array}{ll}\text { Appendix } & 119\end{array}$

$\begin{array}{ll}\text { Index } & 121\end{array}$ 


\section{LIST OF FIGURES}

Figure 1.1. Logical Knowledge Formation.

Figure 1.2. Validation Conditions.

Figure 1.3. Knowledge Assets.

Figure 1.4. Logical Process.

Figure 1.5. Content Reasoning. 43

Figure 1.6. Segmentation Key Process Activities. 46

Figure 2.1. Using the Right Data. 54

Figure 2.2. Content with Context. 54

Figure 2.3. Main Channels of Knowledge

Environment. 71

Figure 3.1. High-level Knowledge Landscape. 84

Figure 3.2. Logical Process Phases. 84 
This page intentionally left blank 


\section{LIST OF TABLES}

Table 1.1. Examples of Knowledge Use. 28

Table 1.2. Logical Knowledge Phases. 35

Table 1.3. Knowledge vs Information Management. $\quad 37$

Table 1.4. Content Reasoning Counterparts. 44

Table 3.1. Knowledge Environment Team Roles. 99 
This page intentionally left blank 


\section{ABOUT THE AUTHOR}

Beverly is the author of Delivering ITSM For Business Maturity: A Practical Framework and a high-performing business technology leader. She is an IT Business Strategist that specializes in information technology service management (ITSM), knowledge management, and business strategies for technology environments. She currently works as an independent consultant, where she provides strategic business and technology management education and consultancy. Beverly has led multiple implementations of knowledge management and ITSM in a variety of industries, such as finance, healthcare, professional services, insurance, and manufacturing.

Beverly's experience includes information and knowledge management, service management, IT governance, organizational transformation, and quality assurance practices. She has a knack for integrating information and people with technology.

Beverly's career in IT started with beta software testing and support. Service Operations is her home in IT. She has a passion for technology and focuses on the valuable ways to balance life in the modern world. Beverly is the Founder of edifyIT, LLC, a company she began in 2009, which provides Business and Technology Management education and training. 
Beverly also has a passion for yoga and is an Experienced Yoga Teacher (E-RYT). Yoga is a big part of her self-care system and she has blended a regular yoga practice into her busy corporate life. It's given her a perfect blend of a life-work balance that's helped her manage modern-day stress. 


\section{PREFACE}

Knowledge management encompasses a broad scope of topics concentrated on a core set of information. Businesses are accustomed to handling and managing the information it generates through systems, interactions with customers, through product development, planning, etc. Knowledge is made up of the human elements to information. The human element gives form and context to data and as a practice business collects knowledge with a resolve to distribute and with anticipation people will share between departments.

Information as a tenant of knowledge is relative to a specific topic and its advanced with details about the topic from a person's experience, learning, and understanding. This is one example of how knowledge comes to be. The idea is to advance information to a state where it represents a comprehensive narrative about the subject. Knowledge combined with human insight, known as tacit knowledge, is often referred to as wisdom. We interchange the use of knowledge and wisdom very closely as if they are the same, but they are not.

Wisdom is a presence and knowledge are an entity, an asset.

For the purposes of this book, our focus is entirely on understanding knowledge based on two perspectives: logical 
and illogical knowledge and achieving good knowledge management practices using modern technology. It isn't as simple as it may seem, and designing a good infrastructure for knowledge systems is one small part. There are many complex areas to consider while creating a knowledge strategy. One area is the knowledge sandpit.

There is a hidden sandpit within knowledge management? The sandpit is how I describe excessive amounts of information being passed off as knowledge. Information comes from data we collect; however, it's not all eligible to be considered knowledge. Knowledge should align to certain conditions associated to a topic. Let's say you have information that meets the criteria at hand, and it's formally approved as useable knowledge. Approach filtering carefully because the context of the content may be illogical (not ideal). Just because content becomes part of a community knowledge repository doesn't mean it's logical (ideal). There is a major problem with unfounded knowledge being passed off as factual and logical knowledge. Illogical knowledge doesn't have a place in business and it can invoke ominous situations when people use or follow illogical knowledge. To avoid a sand trap, rational thinking in businesses managing knowledge is needed today more than ever before.

Knowledge is found everywhere in our advancing world of technology. Technology should be making things easier and in some capacity it is; however, we are a long way away from learning how to balance the use of technology where is deemed helpful. We are in a pivotal time to provide better education on integrating technology and people for usefulness, value, and effectiveness. Notice, I'm not including efficiency. Efficiency doesn't belong here, and being efficient is only meaningful when the task or situation needs it.

The considerable amount of illogical knowledge being used and the refrainment of integrating people and technology in a 
balanced way is a major motivating factor to why I'm writing this book. In today's world, the twenty-first century, it's really important to help bring awareness and understanding on effecting knowledge management successfully. Better understanding and awareness will help increase the value knowledge will bring to your business community. There is a significant difference between illogical and logical knowledge, and I believe investing in a plan to produce logical knowledge is a vital factor for the plan to succeed. It's important to zone content by logical (ideal) and illogical (not ideal). Illogical knowledge carries extra costs and wasted time because of its unfounded sources or because of unreasonable conditions on how the content is considered to be knowledge.

Another reason I'm writing this book on Knowledge is because of its area of interest personally. I wrote a paper in college on self-knowledge and the older (wiser me) wishes to have this paper today. Knowledge is so prevalent in today's world and has massive amounts of tenants to it. Knowledge and service management are major areas of experience in my Information Technology (IT) career. I write this book from this experience and insight.

Knowledge management is a blend of various commodities, and effecting knowledge management is a valuable business asset. It supports communities of interest and can be a time saver when done properly. To do knowledge properly involves comprehensive understanding of knowledge management and use of a distinct strategy to put it in place.

Sharing knowledge in responsible and logical ways is the motivation behind this book. It's something I exercise in business and personal life. When it comes to knowledge, just be open to other possibilities outside of its scientific models and processes to manage it. This book is instrumental to enduring the complexities of managing knowledge in the twenty-first century! 
This page intentionally left blank 


\section{ACKNOWLEDGMENTS}

This project wouldn't have been possible without the opportunities I am grateful to have had during my career in Information Technology and Business. Thank you to each person I worked with along the way, and to the companies I've had the honor to represent with my work.

Knowledge is an area that I'm particularly interested in since school age years. In college I wrote a paper (wish I still had it) on self-knowledge. Although this project focuses on the concepts of illogical and logical knowledge in advanced modern times for business, self-knowledge is a big part of what has guided me through a successful career.

Nobody is more important to me than my family. Their unconditional love and support has helped me grow and succeed in my work.

Thank you to all at Emerald Publishing for their experience to bring my books to the public. 
This page intentionally left blank 


\section{INTRODUCTION}

Knowledge is a complex and confusing area because it's harder to define than basic information. The path that knowledge flows within an organization is equally important to the content being distributed and shared. Knowledge mostly flows bilaterally in various directions. Typically, an organization focuses on knowledge that flows and is shared vertically and horizontally. This isn't enough because there are sources of knowledge in many channels that extend beyond up or down and across. These channels are those linked to the major vertical and horizontal pathways. Knowledge sources are like pockets, pockets connected to the organization layers both internal and external. A good way to describe it is to think about a sponge and its unique permeable surface. The circular pocket pattern on a sponge surface represents pockets of knowledge in an organization. The absorbency of the sponge represents how well knowledge is absorbed and shared. This makes identifying the pockets of knowledge content and how it flows within an organization critical to understand. By comparison to information, knowledge relies heavily on the human aspect and good understanding of existing pockets of knowledge. Information is more exact and flows in single lanes between systems.

Information management focuses on data and activities on a factual basis. Knowledge management focuses on 
individual's experiences, and methods of how knowledge is shared within an organization or community. Information combined with experience creates knowledge. Knowledge helps people in a variety of ways. For instance, learn and understand about business- or work-related topics. Knowledge also helps to solve problems, figure out causes to problems, and serves as a method of education.

One angle to view knowledge is that knowledge management evolved from information management. Knowledge is a much broader area and it is more people centric than dealing with information. Being people centric makes knowledge management more difficult to decipher and express. The challenges to interpret and articulate knowledge is the very cause to producing mass amounts of illogical or useless knowledge. This perspective creates an uncompromising situation and a common belief that collecting knowledge and a drive to store as much knowledge as possible is an effective strategy. It isn't, it's a perspective that will inflict disorder. This perspective doesn't care much about the quality or logical aspect to the inner parts of knowledge. The basis of this book is focused on knowledge management from an illogical and logical standpoint. The ideal perspective to change is approach knowledge management consistently and realistically.

In the information age, the boundaries between information and knowledge are blurred substantially making the task to choose content difficult. This creates issues with data waste, information overload, and the burdens of cost to house useless knowledge. In this book, I talk about methods to avoid these types of issues and how to segment data selectively, filter information to feed into knowledge management, and create context and guidelines for effective knowledge management practices. A good strategy for 
managing knowledge and is one that creates a wellstructured environment to support it.

Poor knowledge can come from an inadequate architecture; difficulties applying content to be useful, too much content, poor quality of content, or inconsistent and poor collection methods. Having good knowledge is attainable but if people can't retrieve or find knowledge they need, then the environment is not useful.

Knowledge is useless without proper context and application. Users need a fundamental understanding on what knowledge is and why the organization needs knowledge management procedures. In my experience, high-level plans for knowledge often do not work and will steer a good plan off course. Succeeding with knowledge management comes from a balanced plan with attention to detail to interconnect the pockets of knowledge, build quality logical knowledge assets, and methods to share them. This helps its users understand knowledge, how to use it, and where to find it.

A balanced plan includes business logic behind the plan and ways the company will manage it.

In this book there is a useable approach to support the creation of logical knowledge from a balanced knowledge management plan. This will aid its readers to understand this complex area. Quality knowledge is a highly effective nontechnical system in a pool of highly technical resources. It helps you to diligently make choices based on need and purpose. This book represents logical knowledge acquired and modernized to fit with current technical systems and tools. 